\title{
Risk factors for respiratory complications after adenotonsillectomy in children with obstructive sleep apnea*
}

\author{
Fatores de risco para complicações respiratórias após adenotonsilectomia \\ em crianças com apneia obstrutiva do sono \\ Renato Oliveira Martins ${ }^{1}$, Nuria Castello-Branco ${ }^{2}$, \\ Jefferson Luis de Barros ${ }^{1}$, Silke Anna Theresa Weber ${ }^{3}$
}

\begin{abstract}
Objective: To identify risk factors for respiratory complications after adenotonsillectomy in children $\leq 12$ years of age with obstructive sleep apnea who were referred to the pediatric ICU (PICU). Methods: A cross-sectional historical cohort study analyzing 53 children after adenotonsillectomy who met predetermined criteria for PICU referral in a tertiary level teaching hospital. The Student's t-test, Mann-Whitney test, and chi-square test were used to identify risk factors. Results: Of the 805 children undergoing adenotonsillectomy between January of 2006 and December of 2012 in the teaching hospital, 53 were referred to the PICU. Twenty-one children (2.6\% of all those undergoing adenotonsillectomy and 39.6\% of those who were referred to the PICU) had respiratory complications. Of those 21,12 were male. The mean age was $5.3 \pm 2.6$ years. A high apneahypopnea index ( $\mathrm{AHI} ; \mathrm{p}=0.0269)$, a high oxygen desaturation index (ODI; $p=0.0082)$, a low $\mathrm{SpO}_{2}$ nadir $(\mathrm{p}=$ $0.0055)$, prolonged orotracheal intubation $(p=0.0011)$, and rhinitis $(p=0.0426)$ were found to be independent predictors of respiratory complications. Some of the complications observed were minor ( $\left.\mathrm{SpO}_{2} 90-80 \%\right)$, whereas others were major ( $\mathrm{SpO}_{2} \leq 80 \%$, laryngospasm, bronchospasm, acute pulmonary edema, pneumonia, and apnea). Conclusions: Among children up to 12 years of age with OSA, those who have a high AHI, a high ODI, a low $\mathrm{SpO}_{2}$ nadir, or rhinitis are more likely to develop respiratory complications after adenotonsillectomy than are those without such characteristics.
\end{abstract}

Keywords: Postoperative complications; Tonsillectomy; Sleep apnea, obstructive.

\section{Introduction}

Obstructive sleep apnea (OSA) affects approximately $4 \%$ of the pediatric population ${ }^{(1)}$ and is associated with significant medical problems, including cardiopulmonary abnormalities ${ }^{(2,3)}$ and failure to thrive. ${ }^{(4)}$

OSA is characterized by increased upper airway resistance leading to disordered sleep. Adenotonsillectomy has become the most common approach in the treatment of pediatric OSA, increasing from $0 \%$ in $1978^{(5)}$ to approximately $77 \%$ in $2005{ }^{(6)}$ because it significantly improves disordered sleep, physical and emotional symptoms, ${ }^{(7)}$ and systemic inflammation secondary to OSA, ${ }^{(2)}$ and because it can reverse cor pulmonale. ${ }^{(3)}$

Adenotonsillectomy is not risk-free; there is the possibility of hemorrhage, dehydration, nausea, vomiting, pain, ${ }^{(8)}$ and need for additional airway support postoperatively. ${ }^{(9-11)}$ In children undergoing adenotonsillectomy for OSA, the rate of respiratory complications requiring medical intervention ranges from $21 \%$ to $36 \% .^{(9,10)}$ OSA

1. Master's Student in Fundamentals of Surgery. Faculdade de Medicina de Botucatu, Universidade Estadual Paulista - FMB-UNESP, São Paulo State University Botucatu School of Medicine - Botucatu, Brazil.

2. Postdoctoral Student in Sleep Medicine. Faculdade de Medicina da Universidade de São Paulo - FMUSP, University of São Paulo School of Medicine - São Paulo, Brazil.

3. Tenured Professor. Department of Ophthalmology, Otolaryngology and Head and Neck Surgery, Faculdade de Medicina de Botucatu, Universidade Estadual Paulista - FMB-UNESP, São Paulo State University Botucatu School of Medicine - Botucatu, Brazil. *Study carried out in the Department of Ophthalmology, Otolaryngology and Head and Neck Surgery, Faculdade de Medicina de Botucatu, Universidade Estadual Paulista - FMB-UNESP, São Paulo State University Botucatu School of Medicine - Botucatu, Brazil. Correspondence to: Renato Oliveira Martins. Departamento de Oftalmologia, Otorrinolaringologia e Cirurgia de Cabeça e Pescoço, Avenida Prof. Montenegro, s/n, Distrito de Rubião Júnior, CEP 18618-970, Botucatu, SP, Brasil.

Tel./Fax: 5514 3811-6256 or 5514 3811-6081.E-mail: renatoceres@yahoo.com.br

Financial support: None.

Submitted: 5 September 2014. Accepted, after review: 3 February 2015. 
is commonly associated with risk factors for respiratory complications. It is important to identify those factors that can increase the risk of postoperative respiratory complications in children with OSA to ensure better quality of care and for safety reasons.

There is a consensus that children with severe OSA should be observed postoperatively. ${ }^{(1)}$ However, there is disagreement over the safest place for clinical observation after surgery: an outpatient setting; a pediatric ward; or a pediatric ICU (PICU). Because of the paucity of evidence-based guidelines and studies for enabling better clinical practice, the objective of this study was to identify risk factors for possible respiratory complications after adenotonsillectomy in children $\leq 12$ years of age with OSA who were referred to the PICU.

\section{Methods}

This was a cross-sectional historical cohort study analyzing 53 children after adenotonsillectomy who met predetermined criteria for PICU referral in a tertiary level teaching hospital.

This study was approved by the Research Ethics Committee of the São Paulo State University Botucatu School of Medicine (Protocol no. CEP 4336-2012).

We included all male and female children 1 to 12 years of age, with adenotonsillar hypertrophy, admitted to the PICU after adenotonsillectomy, between January of 2006 and December of 2012. We excluded children with cardiac, pulmonary, neuromuscular, or chromosomal abnormalities and children with craniofacial anomalies, as well as children concurrently undergoing other surgical procedures associated with adenotonsillectomy, such as myringotomy, insertion of ventilation tubes, and/or diagnostic laryngoscopy. Referral to the ICU was based on clinical and/or polysomnographic criteria, which included age $<3$ years, obesity, underweight, asthma, and/or polysomnographic changes $\left(\mathrm{SpO}_{2}\right.$ nadir $\leq 80 \%, \mathrm{AHI} \geq 10$ events $\left./ \mathrm{h}\right)$.

All patients were evaluated by a single researcher during the perioperative period. Preoperative data were collected with a standardized history-taking questionnaire regarding age, gender, body mass index (BMI), presence of comorbidities-obesity (as defined on the basis of age-specific and gender-specific BMI percentile curves adopted by the World Health Organization [2007], with BMl percentiles $\geq 97$ being a criterion of obesity), asthma, rhinitis, and upper respiratory tract infection (URTI)adenoid size (as determined by examination with a 2.4-mm-diameter rigid endoscope with a 0-degree lens, on the basis of the adenoid/ nasopharyngeal ratio), and tonsil size (as measured by Brodsky's scale)

Cardiorespiratory monitoring to confirm the diagnosis of OSA was performed on an inpatient basis, through the Department of Otolaryngology, for up to 6 months before adenotonsillectomy. The children underwent type 1 polysomnography (Alice; ; Phillips Respironics, Murrysville, PA, USA), or type 111 polysomnography (Stardust 11 ${ }^{\circledast}$; Phillips Respironics), or overnight oximetry to record $\mathrm{SpO}_{2}$ (PV 4000 LCD; Protec Equipamentos MédicoHospitalares, São Paulo, Brazil). The respiratory parameters analyzed were as follows: apneahypopnea index (AHI); hypopnea index (HI); oxygen desaturation index (ODI); and $\mathrm{SpO}_{2}$ nadir. Data were recorded by the software of each device and were scored by a single rater. Oximetry was used to determine $\mathrm{SpO}_{2}$ nadir. Obstructive apnea was defined as a greater than 90\% drop in nasal pressure excursions for at least 2 respiratory cycles, associated with thoracic and/or abdominal effort. Central apnea was defined as an absence of inspiratory effort throughout the event, with the event being $\geq 20$ seconds in duration or lasting 2 respiratory cycles and being associated with an arousal or $\geq 3 \%$ oxygen desaturation. Hypopnea was characterized by a decrease of at least $50 \%$ in nasal pressure excursions, associated with $\geq$ 3\% oxygen desaturation. The ODI was defined as the number of episodes of oxyhemoglobin desaturation $\geq 3 \%$ from baseline $\mathrm{SpO}_{2}$ per hour of sleep and $\geq 10$ seconds in duration. $\mathrm{SpO}_{2}$ nadir was defined as the lowest $\mathrm{SpO}_{2}$ value, regardless of duration. OSA was classified as mild (AHI of 1 to 4.9 events/h), moderate (AHI of 5 to 9.9 events $/ \mathrm{h}$ ), or severe ( $\mathrm{AHI} \geq 10$ events/h), and events were scored according to the recommended rules by the American Academy of Sleep Medicine (2007).

All surgical procedures were supervised, which allowed standardization of the surgical technique and the use of a standardized anesthetic protocol for children with OSA. Tonsillectomies and adenoidectomies were performed with the standard cold technique and a combination of intravenous (propofol [3mg/kg] and alfentanil [50mg/kg]) and inhalational (sevoflurane and/ or $\mathrm{N}_{2} \mathrm{O} / \mathrm{O}_{2}$ 50:50) anesthesia. After surgery, all children were referred, intubated, to the PICU, 
where they remained intubated for up to $6 \mathrm{~h}$ and where they stayed for a minimum of $24 \mathrm{~h}$, in accordance with the guidelines of the facility for children with severe apnea. The children were divided into two groups on the basis of absence of presence of respiratory complications after adenotonsillectomy.

Postoperative respiratory complications were divided into major complications $\left(\mathrm{SpO}_{2} \leq 80 \%\right.$, laryngospasm, bronchospasm, apnea, pneumonia [confirmed by chest X-ray, leukocytosis with a left shift, and fever], and post-obstructive acute pulmonary edema [confirmed by chest X-ray or use of loop diuretics and reintubation]) and minor complications ( $\mathrm{SpO}_{2}$ between $90 \%$ and $80 \%$ requiring airway repositioning). In addition, we assessed duration of orotracheal intubation (OTI) after adenotonsillectomy as well as medical interventions (need for airway repositioning, use of positive pressure devices [continuous positive airway pressure or bilevel positive airway pressure], and reintubation).

\section{Statistical analysis}

Normality of data was tested with the Kolmogorov-Smirnov test, which was applied to all continuous variables in each group. The Student's t-test, Mann-Whitney test, and chi-square test were used for between-group comparisons of the study variables. Multiple linear regression analysis was performed to determine which variables correlated most closely with an increased risk of respiratory complications after adenotonsillectomy.

All tests were performed with Statistica, version 6.0 (StatSoft Inc., Tulsa, OK, USA), and the level of significance was set at $5 \%$.

\section{Results}

Between January of 2006 and December of 2012, 805 adenotonsillectomies were performed in children with OSA in the teaching hospital, and 53 of those children were referred to the PICU. The reasons for referral to the PICU were age < 2 years $(n=2)$; obesity and/or asthma with an $\mathrm{SpO}_{2}$ nadir $\leq 80 \%(\mathrm{n}=10) ;$ an $\mathrm{SpO}_{2}$ nadir $\leq 75 \%$ $(\mathrm{n}=4)$; mild OSA with an $\mathrm{SpO}_{2}$ nadir $\leq 70 \%(\mathrm{n}=$ 1); moderate OSA associated with comorbidities $(\mathrm{n}=5)$ or an $\mathrm{SpO}_{2}$ nadir $\leq 80 \%(\mathrm{n}=2)$; and severe OSA $(n=29)$. Respiratory parameters were recorded by type 1 polysomnography (n
$=7)$, type 111 polysomnography $(\mathrm{n}=30)$, and oximetry $(n=6)$.

Among the comorbidities assessed, rhinitis was the most common, occurring more frequently in the children with respiratory complications than in those without (Table 1). The children with respiratory complications had a higher $\mathrm{AHl}$, a higher $\mathrm{ODI}$, a lower $\mathrm{SpO}_{2}$ nadir, and a longer duration OTl than did those without complications (Table 2). After multiple linear regression analysis, the following independent variables were found to contribute to increasing the risk of respiratory complications after adenotonsillectomy: $\mathrm{AHI}$; $\mathrm{ODI}$; $\mathrm{SpO}_{2}$ nadir; rhinitis; and duration of OTI $\left[p\left(R^{2}\right)=0.0099\right]$; although, individually, no variable showed a close association with the clinical outcome (Table 3).

Of the 53 children studied, 21 (39.6\%) had respiratory complications after adenotonsillectomy. The children were divided into two groups on the basis of absence of presence of respiratory complications (Table 1). The group without complications consisted of 32 children, 16 of whom were male, and the mean age was $6.1 \pm$ 3.1 years (range, 1.6-12 years). The group with complications consisted of 21 children, 12 of whom were male, and the mean age was $5.3 \pm$ 2.6 years (range, 2.4-12 years).

Seven children had minor respiratory complications ( $\left.\mathrm{SpO}_{2} 90-80 \%\right)$, and 14 children had major respiratory complications $\left(\mathrm{SpO}_{2} \leq 80 \%\right.$ $[n=2]$; laryngospasm [ $n=9]$; bronchospasm $[n=5]$; intraoperative bronchospasm $[n=2]$; apnea [n=1]; pneumonia [ $n=1]$; and acute pulmonary edema $[n=3]$; Table 4$)$. The group with respiratory complications remained in the PICU for $\geq 24 \mathrm{~h}$, and the main medical interventions were antibiotic therapy $(n=1)$ for pneumonia, use of loop diuretics $(n=3)$ for acute pulmonary edema, continuous administration of nebulized bronchodilator or adrenaline ( $n=$ 12) for bronchospasm and laryngospasm, and reintubation $(n=3)$ for acute pulmonary edema and severe bronchospasm in the presence of URTI (Table 4). The postoperative mortality rate was zero, and the children with and without respiratory complications remained hospitalized for $3 \pm 1$ days and $5 \pm 2$ days, respectively.

The respiratory complications observed after adenotonsillectomy are described individually in Table 4. 
Table 1 - Comparison of demographic data and comorbidities in children, by absence or presence of respiratory complications after adenotonsillectomy. ${ }^{a}$

\begin{tabular}{|c|c|c|c|}
\hline \multirow[t]{3}{*}{ Variable } & \multicolumn{2}{|c|}{$\begin{array}{l}\text { Respiratory complications after } \\
\text { adenotonsillectomy }\end{array}$} & \multirow[t]{3}{*}{$\mathrm{p}$} \\
\hline & Absence & Presence & \\
\hline & $(n=32)$ & $(n=21)$ & \\
\hline Male/Female & $16 / 16$ & $12 / 9$ & $0.6062^{*}$ \\
\hline Age, years & $6.2 \pm 3.1$ & $5.3 \pm 2.6$ & $0.2820^{* * *}$ \\
\hline$<3$ & 4 & 3 & $0.4040^{* * * *}$ \\
\hline $3-6$ & 13 & 10 & \\
\hline $7-9$ & 8 & 7 & \\
\hline $10-12$ & 7 & 1 & \\
\hline $\mathrm{BMl}, \mathrm{kg} / \mathrm{m}^{2}$ & $19.28 \pm 5.27$ & $18.76 \pm 5.19$ & $0.7257^{* *}$ \\
\hline$<3$ rd percentile & 0 & 2 & $0.8489^{* * *}$ \\
\hline$\geq$ 3rd percentile and $<85$ th percentile & 14 & 7 & \\
\hline$\geq 85$ th percentile and $<97$ th percentile & 5 & 2 & \\
\hline$\geq 97$ th percentile & 13 & 10 & \\
\hline \multicolumn{4}{|l|}{ Comorbidity } \\
\hline Obesity & 13 & 10 & $0.4931^{*}$ \\
\hline Asthma & 4 & 6 & $0.1164^{*}$ \\
\hline Rhinitis $^{\mathrm{b}}$ & 20 & 25 & $0.0426^{*}$ \\
\hline Current URTI & 0 & 2 & $0.0668^{*}$ \\
\hline
\end{tabular}

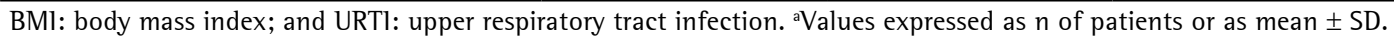

${ }^{\text {b}}$ Variable selected for multiple linear regression analysis. ${ }^{*}$ Chi-square test; ${ }^{* *}$ Student's t-test; and ${ }^{* * *}$ Mann-Whitney test.

Table 2 - Comparison of polysomnographic data, duration of orotracheal intubation, and adenoid and tonsil size in children, by absence or presence of respiratory complications after adenotonsillectomy.

\begin{tabular}{|c|c|c|c|c|c|}
\hline \multirow[t]{2}{*}{ Variable } & \multicolumn{2}{|c|}{ Absence of complications } & \multicolumn{2}{|c|}{ Presence of complications } & \multirow[t]{2}{*}{$\mathrm{p}$} \\
\hline & $\mathrm{n}$ of patients & Mean \pm SD & $\mathrm{n}$ of patients & Mean \pm SD & \\
\hline \multicolumn{6}{|c|}{ Polysomnographic variable } \\
\hline $\mathrm{AHI}$, events $/ \mathrm{h}^{\mathrm{a}}$ & 24 & $18.1 \pm 11.2$ & 13 & $28.6 \pm 16.3$ & $0.0269^{*}$ \\
\hline $\mathrm{HI}$, events/h & 24 & $5.8 \pm 6.0$ & 13 & $10.5 \pm 10.4$ & $0.0882^{*}$ \\
\hline ODl, episodes $/ \mathrm{h}^{\mathrm{a}}$ & 18 & $15.3 \pm 9.4$ & 12 & $29.8 \pm 18.4$ & $0.0082^{*}$ \\
\hline $\mathrm{SpO}_{2}$ nadir, $\% \%^{\mathrm{a}}$ & 28 & $76.8 \pm 10.9$ & 15 & $64.4 \pm 16.9$ & $0.0055^{*}$ \\
\hline PO duration of $0 \mathrm{Tl}, \mathrm{h}^{\mathrm{a}}$ & 32 & $1.8 \pm 2.0$ & 21 & $5.0 \pm 4.8$ & $0.0011^{*}$ \\
\hline \multicolumn{6}{|l|}{ Adenoid and tonsil size } \\
\hline Adenoid, ANR & 30 & $78 \pm 17$ & 17 & $87 \pm 13$ & $0.0705^{*}$ \\
\hline \multicolumn{6}{|c|}{ Tonsils, Brodsky's scale } \\
\hline 1 & 0 & - & 0 & - & $0.3512^{* *}$ \\
\hline 2 & 4 & - & 2 & - & \\
\hline 3 & 18 & - & 10 & - & \\
\hline 4 & 10 & - & 9 & - & \\
\hline
\end{tabular}

AlH: apnea-hypopnea index; HI: hypopnea index; ODI: oxygen desaturation index; P0: postoperative; OTI: orotracheal intubation; and ANR: adenoid/nasopharyngeal ratio. ${ }^{a}$ Variables selected for multiple linear regression analysis. *Student's t-test; and **Mann-Whitney test.

\section{Discussion}

Of the 805 children undergoing adenotonsillectomy between January of 2006 and December of 2012 in the teaching hospital, 21 $(2.6 \%)$ had postoperative respiratory complications. This finding is similar to the results of other studies, in which the rate of respiratory complications ranged from $1.3 \%$ to $13.4 \% .{ }^{(12-16)}$ Analysis of the children at high risk for complications who were referred to the PICU $(n=53)$ revealed that the rate of respiratory complications was $39.6 \%$, which is also consistent with the findings of other studies, in which rates ranged from 
Table 3 - Multiple linear regression analysis considering respiratory complications after adenotonsillectomy as a dependent variable. ${ }^{\text {a }}$

\begin{tabular}{lcccccccc}
\hline $\begin{array}{c}\text { Independent } \\
\text { variable }\end{array}$ & $\begin{array}{c}\text { Absence of } \\
\text { complications }\end{array}$ & $\begin{array}{c}\text { Presence of } \\
\text { complications }\end{array}$ & Beta & $\begin{array}{c}\text { Partial } \\
\text { regression } \\
\text { coefficient }\end{array}$ & $\begin{array}{c}\text { Standard } \\
\text { error }\end{array}$ & $p$ & $\mathrm{R}^{2}$ & $\mathrm{p}\left(\mathrm{R}^{2}\right)$ \\
\hline $\mathrm{AHl}$ & $18.1 \pm 11.2$ & $28.6 \pm 16.3$ & -0.0276 & -0.0009 & 0.0073 & 0.8972 & 0.3722 & $<0.0099$ \\
$\mathrm{ODl}$ & $15.3 \pm 9.4$ & $29.8 \pm 18.4$ & 0.2730 & 0.0082 & 0.0075 & 0.2798 & & \\
$\mathrm{SpO}_{2}$ nadir & $76.8 \pm 10.9$ & $64.4 \pm 16.9$ & -0.0077 & -0.0003 & 0.0062 & 0.9650 & & \\
Rhinitis & 20 & 25 & 0.2679 & 0.3265 & 0.1843 & 0.0863 & & \\
PO duration of & $1.8 \pm 2.0$ & $5.0 \pm 4.8$ & 0.3781 & 0.0527 & 0.0267 & 0.0568 & & \\
OTl, h & & & & & & & & \\
\hline
\end{tabular}

AlH: apnea-hypopnea index; ODl: oxygen desaturation index; P0: postoperative; and OTI: orotracheal intubation. avalues expressed as mean \pm SD or as $n$ of patients.

$25 \%$ to $60 \% .^{(11,17-21)}$ it is of note that none of the children who had post-adenotonsillectomy follow-up in the pediatric ward had any major respiratory complications requiring transfer to the PICU.

The postoperative referral of the 53 children to the PICU was motivated by the presence of OSA associated with one or more risk factors. According to the literature, children with OSA aged $<2$ years ${ }^{(9,11,17,18)}$ or $<3$ years ${ }^{(21)}$ and presenting with obesity, ${ }^{(9,12,15,22-24)}$ underweight, ${ }^{(9,21)}$ asthma, ${ }^{(11,14)}$ polysomnographic changes ( $\mathrm{SpO}_{2}$ nadir $\leq 80 \% \%^{(11)}$ or $<72 \%,{ }^{(9,15,19)} \mathrm{AHl} \geq 24$ events/ $/{ }^{2},{ }^{(17)}$ high $\mathrm{Hl}$ and/ or high $\mathrm{AHI}),{ }^{(15)} \mathrm{CO}_{2}$ pressure $>45 \mathrm{mmHg}$ and $\mathrm{SpO}_{2}<86 \%$, ${ }^{(21)}$ intraoperative laryngospasm, ${ }^{(17)}$ or systemic comorbidities (neuromuscular abnormalities, ${ }^{(9,11,20)}$ craniofacial anomalies, ${ }^{(9,11,20)}$ cardiac abnormalities, ${ }^{(11,12,20,25)}$ and chromosomal abnormalities) ${ }^{(11,12)}$ have increased rates of respiratory complications after adenotonsillectomy. However, after this study's analyses of the results for postoperative respiratory complications, the local department of otolaryngology discontinued the routine practice of referring patients $<12$ years of age with OSA and/or risk factors to the PICU after adenotonsillectomy. What is recommended is that a sleep study be performed to determine the severity of the respiratory disorder and a thorough clinical history be taken to identify risk factors. For patients with severe OSA associated with severe comorbidities (chromosomal, cardiac, and neuromuscular abnormalities, as well as craniofacial anomalies) and/or children $<2$ years of age, the recommendation for postoperative observation in the PICU still applies.

The risk factors that could predict respiratory complications after adenotonsillectomy were polysomnographic parameters (high $\mathrm{AHI}$ [mean of 28.6 events/h]; high ODI [mean of 29.8 episodes/h]; and low $\mathrm{SpO}_{2}$ nadir [mean of $64.4 \%$ ]), presence of rhinitis, and prolonged postoperative OTI (Table 2).

A higher $\mathrm{AHI}$, a higher ODl, and a lower $\mathrm{SpO}_{2}$ nadir on the preoperative sleep study translate to a higher prevalence of respiratory complications in children. Our results were similar to those found in other studies that correlated polysomnographic findings with postoperative respiratory complications and medical interventions. $(10,11,15,17,26)$ Schroeder et al. ${ }^{(26)}$ observed that $43 \%$ of the children with an $\mathrm{AHl}>25$ events/h required some intervention as a result of respiratory complications. Another study showed that a higher $\mathrm{AHI}$ (mean of 31.8 events/h), a higher $\mathrm{HI}$ (mean of 22.6 events/h), and a lower $\mathrm{SpO}_{2}$ nadir (mean of $71.7 \%$ ) translate to a stronger correlation with respiratory complications, and that desaturation events were the ones most commonly requiring oxygen supplementation. ${ }^{(15)}$ Therefore, it is clear that determining apnea severity via a sleep study (polysomnography) before surgery is important in predicting the risk of possible postoperative respiratory complications.

Among the comorbidities assessed, only rhinitis was found to be statistically significant in the group with respiratory complications. Because children with severe OSA have greater airway collapsibility ${ }^{(27,28)}$ and are more susceptible to the respiratory-depressant effects of anesthetics and opioids, ${ }^{(29,30)}$ it is possible that rhinitis associated with increased secretions and upper airway edema can contribute to greater resistance and, consequently, to an increased likelihood of perioperative respiratory complications.

Although several studies in the literature have demonstrated that age $<2$ years $^{(9,11,17,18)}$ or $<3$ years, ${ }^{(21)}$ obesity, ${ }^{(9,12,15,22-24)}$ and asthma ${ }^{(11,14)}$ are related to a greater likelihood of respiratory 


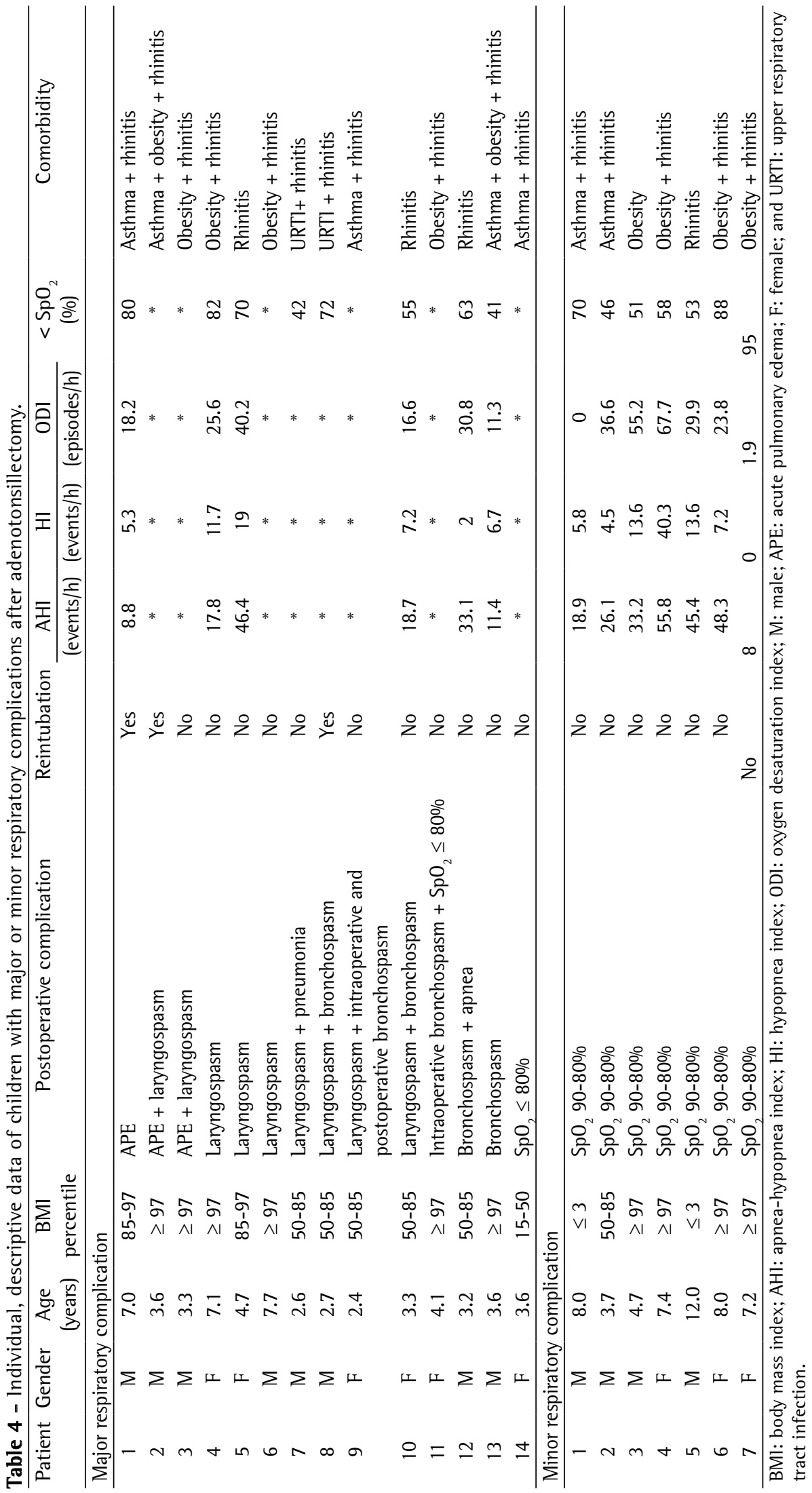


complications after adenotonsillectomy, this study found no statistically significant differences among these variables in terms of the occurrence of respiratory events (Table 1). It may be that this lack of significance is due to the small sample size, to the fact that this was a group of children at increased risk for respiratory complications, and to the fact that the children were similar in terms of comorbidities.

Duration of OTI (Table 2) was statistically longer in patients with respiratory complications, corroborating Schroeder Jr. et al., ${ }^{(26)}$ who demonstrated that delaying extubation can increase the likelihood of respiratory complications in a group who is already at high risk. Therefore, children undergoing adenotonsillectomy for OSA associated with comorbidities who remained intubated after surgery had increased complication rates and, consequently, prolonged hospital stays.

This study was limited by its small sample size, surgeons' varied preferences of where postoperative observation should occur, and a possible bias in selecting children for polysomnography. A prospective study with a larger sample size is needed to determine possible risk factors associated with an increased likelihood of respiratory complications after adenotonsillectomy. ${ }^{(17)}$

The results of the present study indicate that, among children up to 12 years of age diagnosed with OSA, those who have a high AHI, a high $\mathrm{ODI}$, and a low $\mathrm{SpO}_{2}$ nadir on preoperative polysomnography, as well as rhinitis, are more likely to develop respiratory complications after adenotonsillectomy than are those without such characteristics.

\section{References}

1. Baugh RF, Archer SM, Mitchell RB, Rosenfeld RM, Amin R, Burns JJ, et al. Clinical practice guideline: tonsillectomy in children. Otolaryngol Head Neck Surg. 2011;144(1 Suppl):S1-30. http://dx.doi. org/10.1177/0194599810389949

2. Goldbart AD, Levitas A, Greenberg-Dotan S, Ben Shimol S, Broides A, Puterman M, et al. B-type natriuretic peptide and cardiovascular function in young children with obstructive sleep apnea. Chest. 2010;138(3):52835. http://dx.doi.org/10.1378/chest.10-0150

3. Cohen S, Springer C, Perles Z, Koplewitz BZ, Avital A, Revel-Vilk S. Cardiac, lung, and brain thrombosis in a child with obstructive sleep apnea. Pediatr Pulmonol. 2010;45(8):836-9. http://dx.doi.org/10.1002/ppul.21256

4. Freezer NJ, Bucens IK, Robertson CF. Obstructive sleep apnoea presenting as failure to thrive in infancy. $\mathrm{J}$ Paediatr Child Health. 1995;31(3):172-5. http://dx.doi. $\operatorname{org} / 10.1111 / \mathrm{j} .1440-1754.1995 . t b 00779 . x$
5. Rosenfeld RM, Green RP. Tonsillectomy and adenoidectomy: changing trends. Ann Otol Rhinol Laryngol. 1990;99(3 Pt 1):187-91.

6. Erickson BK, Larson DR, St Sauver JL, Meverden RA, Orvidas LJ. Changes in incidence and indications of tonsillectomy and adenotonsillectomy, 1970-2005. Otolaryngol Head Neck Surg. 2009;140(6):894-901. http://dx.doi.org/10.1016/j.otohns.2009.01.044

7. Tran KD, Nguyen CD, Weedon J, Goldstein NA. Child behavior and quality of life in pediatric obstructive sleep apnea. Arch Otolaryngol Head Neck Surg. 2005;131(1):52-7. http://dx.doi.org/10.1001/archotol.131.1.52

8. Brigger MT, Brietzke SE. Outpatient tonsillectomy in children: a systematic review. Otolaryngol Head Neck Surg. 2006;135(1):1-7. http://dx.doi.org/10.1016/j. otohns.2006.02.036

9. Rosen GM, Muckle RP, Mahowald MW, Goding GS, Ullevig C. Postoperative respiratory compromise in children with obstructive sleep apnea syndrome: can it be anticipated? Pediatrics. 1994;93(5):784-8.

10. McColley SA, April MM, Carroll JL, Naclerio RM, Loughlin GM. Respiratory compromise after adenotonsillectomy in children with obstructive sleep apnea. Arch Otolaryngol Head Neck Surg. 1992;118(9):940-3. http://dx.doi. org/10.1001/archotol.1992.01880090056017

11. Wilson K, Lakheeram 1, Morielli A, Brouillette R, Brown K. Can assessment for obstructive sleep apnea help predict postadenotonsillectomy respiratory complications? Anesthesiology. 2002;96(2):313-22. http://dx.doi. org/10.1097/00000542-200202000-00015

12. Tweedie DJ, Bajaj Y, Ifeacho SN, Jonas NE, Jephson CG, Cochrane LA, et al. Peri-operative complications after adenotonsillectomy in a UK pediatric tertiary referral centre. Int J Pediatr Otorhinolaryngol. 2012;76(6):80915. http://dx.doi.org/10.1016/j.ijporl.2012.02.048

13. Biavati MJ, Manning SC, Phillips DL. Predictive factors for respiratory complications after tonsillectomy and adenoidectomy in children. Arch Otolaryngol Head Neck Surg. 1997;123(5):517-21. http://dx.doi.org/10.1001/ archotol.1997.01900050067009

14. Kalra M, Buncher R, Amin RS. Asthma as a risk factor for respiratory complications after adenotonsillectomy in children with obstructive breathing during sleep. Ann Allergy Asthma Immunol. 2005;94(5):549-52. http:// dx.doi.org/10.1016/S1081-1206(10)61132-5

15. Jaryszak EM, Shah RK, Vanison CC, Lander L, Choi SS. Polysomnographic variables predictive of adverse respiratory events after pediatric adenotonsillectomy. Arch Otolaryngol Head Neck Surg. 2011;137(1):15-8. http://dx.doi.org/10.1001/archoto.2010.226

16. Suen JS, Arnold JE, Brooks LJ. Adenotonsillectomy for treatment of obstructive sleep apnea in children. Arch Otolaryngol Head Neck Surg. 1995;121(5):525-30. http:// dx.doi.org/10.1001/archotol.1995.01890050023005

17. Hill CA, Litvak A, Canapari C, Cummings B, Collins C, Keamy DG, et al. A pilot study to identify pre- and perioperative risk factors for airway complications following adenotonsillectomy for treatment of severe pediatric OSA. Int J Pediatr Otorhinolaryngol. 2011;75(11):1385-90. http://dx.doi.org/10.1016/j.ijporl.2011.07.034

18. McCormick ME, Sheyn A, Haupert M, Thomas R, Folbe AJ. Predicting complications after adenotonsillectomy in children 3 years old and younger. Int $\mathrm{J}$ Pediatr Otorhinolaryngol. 2011;75(11):1391-4. http://dx.doi. org/10.1016/j.ijporl.2011.07.035 
19. Shine NP, Coates HL, Lannigan FJ, Duncan AW Adenotonsillar surgery in morbidly obese children: routine elective admission of all patients to the intensive care unit is unnecessary. Anaesth Intensive Care. 2006;34(6):724-30.

20. Brown KA, Morin 1, Hickey C, Manoukian JJ, Nixon GM, Brouillette RT. Urgent adenotonsillectomy: an analysis of risk factors associated with postoperative respiratory morbidity. Anesthesiology. 2003;99(3):586-95. http:// dx.doi.org/10.1097/00000542-200309000-00013

21. Ruboyianes JM, Cruz RM. Pediatric adenotonsillectomy for obstructive sleep apnea. Ear Nose Throat J. 1996;75(7):430-3.

22. Nafiu 00, Green GE, Walton S, Morris M, Reddy S, Tremper KK. Obesity and risk of peri-operative complications in children presenting for adenotonsillectomy. Int $\mathrm{J}$ Pediatr Otorhinolaryngol. 2009;73(1):89-95. http:// dx.doi.org/10.1016/j.ijporl.2008.09.027

23. Fung E, Cave D, Witmans M, Gan K, El-Hakim H. Postoperative respiratory complications and recovery in obese children following adenotonsillectomy for sleepdisordered breathing: a case-control study. Otolaryngol Head Neck Surg. 2010;142(6):898-905. http://dx.doi. org/10.1016/j.otohns.2010.02.012

24. Gleich SJ, Olson MD, Sprung J, Weingarten TN, Schroeder DR, Warner D0, et al. Perioperative outcomes of severely obese children undergoing tonsillectomy. Paediatr Anaesth. 2012;22(12):1171-8. http://dx.doi. org/10.1111/j.1460-9592.2012.03905.x
25. Kalra M, Kimball TR, Daniels SR, LeMasters G, Willging PJ, Rutter M, et al. Structural cardiac changes as a predictor of respiratory complications after adenotonsillectomy for obstructive breathing during sleep in children. Sleep Med. 2005;6(3):241-5. http://dx.doi.org/10.1016/j. sleep.2004.10.004

26. Schroeder JW Jr, Anstead AS, Wong H. Complications in children who electively remain intubated after adenotonsillectomy for severe obstructive sleep apnea. Int J Pediatr Otorhinolaryngol. 2009;73(8):1095-9. http://dx.doi.org/10.1016/j.jporl.2009.04.007

27. Gozal D, Burnside MM. Increased upper airway collapsibility in children with obstructive sleep apnea during wakefulness. Am J Respir Crit Care Med. 2004;169(2):163-7. http:// dx.doi.org/10.1164/rccm.200304-5900C

28. Marcus CL, McColley SA, Carroll JL, Loughlin GM, Smith PL, Schwartz AR. Upper airway collapsibility in children with obstructive sleep apnea syndrome. J Appl Physiol (1985). 1994;77(2):918-24.

29. Brown KA, Laferrière A, Moss IR. Recurrent hypoxemia in young children with obstructive sleep apnea is associated with reduced opioid requirement for analgesia. Anesthesiology. 2004;100(4):806-10; discussion 5A.

30. Waters KA, McBrien F, Stewart P, Hinder M, Wharton S. Effects of OSA, inhalational anesthesia, and fentanyl on the airway and ventilation of children. J Appl Physiol (1985). 2002;92(5):1987-94. 